\title{
Congenital myopathy, Paradas type
}

INSERM

\section{Source}

INSERM. (1999). Orphanet: an online rare disease and orphan drug data base. Congenital myopathy, Paradas type. ORPHA:199329

Paradas type congenital myopathy is an early-onset form of dysferlinopathy presenting with postnatal hypotonia, weakness in the proximal lower limbs and neck flexor muscles at birth and delayed motor development. 